\title{
Testosterone replacement therapy among HIV-infected men in the CFAR Network of Integrated Clinical Systems
}

\author{
Ramona Bhatia $^{\mathrm{a}}$, Adam B. Murphy ${ }^{\mathrm{b}}$, James L. Raper ${ }^{\mathrm{c}}$, Gabriel Chamie ${ }^{\mathrm{d}}$, Mari M. Kitahata ${ }^{\mathrm{e}}$, \\ Daniel R. Drozd ${ }^{\mathrm{e}}$, Kenneth Mayer ${ }^{f}$, Sonia Napravnik ${ }^{g}$, Richard Moore ${ }^{\mathrm{h}}$, and Chad \\ Achenbach on behalf of the Centers for AIDS Research (CFAR) Network of Integrated \\ Clinical Systems (CNICS)
}

anstitute for Public Health and Medicine, Northwestern University, Chicago bepartment of Urology, Northwestern University, Chicago, Illinois 'Department of Medicine, Division of Infectious Diseases, University of Alabama at Birmingham, Birmingham, Alabama division of HIV/AIDS, San Francisco General Hospital, University of California, San Francisco, California eDepartment of Medicine, Division of Allergy \& Infectious Diseases, University of Washington, Seattle, Washington fDepartment of Global Health and Population, Fenway Community Health Center of

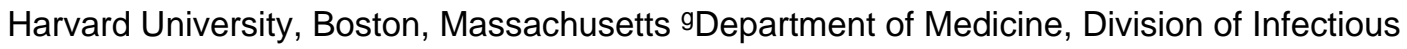
Diseases, University of North Carolina, Chapel Hill, North Carolina hDivision of Infectious Diseases, Johns Hopkins University, Baltimore, Maryland 'Department of Medicine, Division of Infectious Diseases, Northwestern University, Chicago, Illinois, USA

\begin{abstract}
Objective-The objectives of this study were to determine the rate of testosterone replacement therapy (TRT) initiation, TRT predictors and associated monitoring in HIV-infected men.

Design-A multisite cohort study.

Methods-We examined TRT initiation rates and monitoring among adult HIV-infected men in routine care at seven sites in the Centers for AIDS Research (CFAR) Network of Integrated Clinical Systems (CNICS) from 1996 to 2011. We determined TRT predictors using Cox regression modelling.
\end{abstract}

Results-Of 14454 men meeting inclusion criteria, TRT was initiated in 1482 (10\%) with an initiation rate of 19.7/1000 person-years [95\% confidence interval (95\% CI) 18.7-20.7]. In the multivariable model, TRT was significantly associated with age at least 35 years, white race, diagnosis of AIDS wasting, hepatitis $\mathrm{C}$ coinfection, protease inhibitor based antiretroviral therapy and nadir $\mathrm{CD}^{+}$cell count of 200 cells/ $\mu$ or less. Overall, 1886 out of $14454(13 \%)$ had testosterone deficiency. Among those initiating TRT, 992 out of 1482 (67\%) had a pre-TRT serum

(C) 2014 Wolters Kluwer Health | Lippincott Williams \& Wilkins

Correspondence to Ramona Bhatia, Institute for Public Health and Medicine, Northwestern University Feinberg School of Medicine, 645N. Michigan Ave. Suite 1058, Chicago, IL 60611, USA. Tel: +1 312503 9000; fax: +1 312503 8800; ramona-

bhatia@northwestern.edu.

Conflicts of interest

We have no conflicts of interest to disclose. 
total testosterone measured, and deficiency [<300 ng/dl (10.4 nmol/l)] was found in 360 out of $1482(24 \%)$. Post-TRT serum total testosterone was measured within 6 months of TRT initiation in 377 out of $1482(25 \%)$ men.

Conclusion-TRT was common in HIV-infected men, though evidence for pre-TRT testosterone deficiency was lacking in 76\%. Endocrine guidelines for post-TRT monitoring were uncommonly followed. Given cardiovascular and other risks associated with TRT, efforts should focus on understanding factors driving these TRT practices in HIV-infected men.

\section{Keywords}

HIV; hormone replacement therapy; hypogonadism; men's health; patient monitoring; testosterone

\section{Background}

Global testosterone sales have increased 12-fold over the last decade, and the USA is the second leading consumer worldwide [1]. Androgen use tripled from 2001 to 2011 in the U.S., with $2.9 \%$ of men over 40 years of age on testosterone replacement therapy (TRT) [2]. Establishing biochemical testosterone deficiency is recommended before TRT initiation [3], yet up to $83 \%$ of men on TRT lack pretreatment testosterone measurements [4]. Direct-toconsumer marketing and the availability of specialty clinics and transdermal preparations may contribute to TRT overuse in the USA $[1,5,6]$. This is concerning in light of recent studies suggesting that TRT may increase the risk of cardiovascular events $[7,8]$, including myocardial infarction $[9,10]$, stroke [10], thrombosis [11] and death [10], though these remain areas of ongoing investigation.

HIV is associated with testosterone deficiency [12] in up to $70 \%$ of men, a finding that persists despite successful antiretroviral therapy (ART) [13], and hypogonadism is expected to increase, as this population continues to age [14]. Yet, little is known about TRT among HIV-infected men. In a report from the early ART-era, TRT prevalence was 19\%, though pre-TRT testosterone deficiency and post-TRT monitoring were not assessed [15]. In this report, we describe TRT initiation rates and predictors and associated monitoring among HIV-infected men in a large, multicentre U.S. cohort.

\section{Materials and methods}

The Centers for AIDS Research (CFAR) Network of Integrated Clinical Systems (CNICS) electronically collects and standardizes socio-demographic, clinical, laboratory and medication data from inpatient and outpatient encounters of over $28000 \mathrm{HIV}$-infected individuals at eight US sites [16]. We performed a cohort study of adult HIV-infected men seen at one of the seven CNICS clinical sites in which TRT data were available from 1996 to 2011. We excluded men on TRT prior to or within 30 days after cohort entry or with unknown TRT initiation date. TRT initiation was determined on the basis of documentation of transdermal (gel, patch or solution), intramuscular (testosterone cypionate or enanthate), oral or implantable formulations in pharmacy dispensing records, electronic medical records and/or chart abstractions. We defined testosterone deficiency as serum total testosterone less 
than $300 \mathrm{ng} / \mathrm{dl}(10.4 \mathrm{nmol} / \mathrm{l})$ based on US endocrinology practice guidelines [3].

Comorbidities were documented by the providers in the medical record.

We calculated TRT initiation rate as the number of TRT initiation events per person-years of follow-up time from cohort entry to initial TRT date, loss to follow-up or death. We assessed predictors of TRT initiation with univariable and multivariable Cox regression modelling. Statistical analyses were performed using SAS 9.2 (SAS Institute Inc., Cary, North Carolina, USA). This study was approved by the Northwestern University Institutional Review Board.

\section{Results}

There were 14454 men without evidence of TRT prior to CNICS entry with 75173 personyears of follow-up time (Table 1). TRT was initiated in $1482(10 \%)$ men at a median age of 44 [interquartile range (IQR) 38-51] years. The median time between cohort enrolment and TRT initiation was 868 days (IQR 280-1907). Two TRT preparations were initiated on the same day for $102 \mathrm{men}$. Of the 1584 incident medications, 624 (39\%) were intramuscular, $503(32 \%)$ were transdermal, one $(0.1 \%)$ was oral and $456(29 \%)$ were unspecified.

We calculated a TRT initiation rate of 19.7/1000 person-years [95\% confidence interval (95\% CI) 18.7-20.7]. Higher rates of TRT initiation were associated with age at least 35 years, white race, MSM HIV risk factor, diagnosis of AIDS wasting, protease inhibitor based ART, nadir $\mathrm{CD} 4^{+} \mathrm{T}$-lymphocyte cell count $\left(\mathrm{CD} 4^{+}\right)$of 200 cells $/ \mu 1$ or less, nonsmoking and absence of alcohol abuse.

In a multivariable model including all variables in the Table 1 and CNICS site, TRT initiation was independently associated with age at least 35 years, white race, diagnosis of AIDS wasting, hepatitis $\mathrm{C}$ coinfection, protease inhibitor-based ART and nadir $\mathrm{CD} 4^{+}$cell count of 200 cells/ $\mu 1$ or less (Table 1 ).

During cohort follow-up, 6168 of 14454 (43\%) men had at least one serum total testosterone measurement, and 1886 of 6168 (31\%) had testosterone deficiency. Of the men with testosterone deficiency, 1119 (59\%) did not initiate TRT.

Among the 1482 men initiating TRT, pre-TRT serum total testosterone level was measured in 992 (67\%), with a median average pretreatment level of 358 (IQR 248-499) ng/dl [12.4 (IQR 8.6-17.3) nmol/l]. Pre-TRT testosterone deficiency was found in 360 (24\%). Serum total testosterone was measured at least once after TRT initiation in $898(61 \%)$, with a median maximum post-TRT level of 569 (IQR 370-841) ng/dl [19.7 (IQR 12.8-29.2) $\mathrm{nmol} / \mathrm{l}$ ]. Median time to first post-TRT serum total testosterone measurement was 303 (IQR 104-885) days. The first post-TRT serum total testosterone measurement occurred within 6 months of TRT initiation in 377 (25\%) men.

Over half $(55 \%, 812 / 1482)$ of those initiating TRT were over age 40. In this group, 273 (34\%) and 97 (12\%) had pre and 6-month post-TRT prostate-specific antigen (PSA) measurements, respectively. 


\section{Discussion}

In this large, multicentre cohort of HIV-infected men, the TRT initiation rate (19.7/1000 person-years) was over 2.5 times higher than that reported from insurance claims for US adult men in 2011 (7.57/1000 person-years) [5].

Endocrine Society Clinical Practice Guidelines [3] state that TRT is indicated for symptomatic men with unequivocal biochemical androgen deficiency. In one-third (490/1482) of men initiating TRT in CNICS, pre-TRT serum total testosterone levels were unavailable or unmeasured. Only 360 of 1482 (24\%) men initiating TRT had laboratoryconfirmed testosterone deficiency [serum total testosterone $<300 \mathrm{ng} / \mathrm{dl}(10.4 \mathrm{nmol} / \mathrm{l})$ ], similar to rates from general male populations initiating TRT (12-40\%) [5]. Further, only 273 of 812 (34\%) men over age 40 for whom pre-TRT PSA levels are recommended [3] underwent PSA testing, consistent with other reports (34.9\% [4]). These data suggest that TRT may be commonly administered to HIV-infected men without adequate baseline laboratory evaluation and establishment of recommended indications.

We propose several reasons for higher TRT initiation rates among HIV-infected men. Symptomatology associated with hypogonadism, such as fatigue, psychosexual dysfunction and erectile dysfunction [2], may occur more commonly in HIV-infected men and prompt empiric TRT. HIV-infected men may also have greater opportunity to be offered TRT during frequent provider visits. In addition, AIDS wasting and low nadir $\mathrm{CD} 4^{+}$cell count, proxies for end-stage AIDS, predicted TRT in our study. TRT is indicated for HIV-infected men with low testosterone and AIDS-associated weight loss [3]; however, only $4 \%$ ever had AIDS wasting, suggesting that this was not a major contributor. Finally, protease inhibitor use was associated with TRT. Older protease inhibitor based ART is implicated in lipodystrophy and fat redistribution. Body morphologic changes associated with lipodystrophy can be similar to those of testosterone deficiency and may lead to TRT. Protease inhibitors may also enhance peripheral conversion of testosterone to estradiol, resulting in symptoms of hypogonadism [12].

We found inadequate post-TRT monitoring. Endocrinology guidelines recommend monitoring serum testosterone levels 3-6 months after TRT initiation [3], yet these measurements were lacking in 39\% and obtained within the first 6 months in only $25 \%$ of men. Although some patients may have declined testing or received testing outside CNICS, these findings strongly suggest that that HIV providers may not follow recommended monitoring guidelines.

CNICS is limited by the ability to consistently capture data on serum testosterone and PSA testing and TRT obtained from providers outside clinical sites, potentially leading to underreporting of pre-TRT deficiency, post-TRT monitoring and/or TRT initiation. This could partially explain the high proportion (59\%) of men with biochemical testosterone deficiency in the cohort who did not appear to initiate TRT. In addition, it is possible that alternative diagnostic tests were used for determining pre-TRT testosterone deficiency and post-TRT monitoring. Elevations in sex-hormone binding globulin (SHBG) in HIV-infected men may result in low serum-free (bioavailable) testosterone but seemingly normal serum 
total testosterone $[17,18]$, prompting some to utilize serum-free testosterone to screen for deficiency and/or monitor response to TRT in men with HIV [19]. Serum-free testosterone and SHBG laboratory data are inconsistently captured in CNICS and were not utilized for these analyses, which could have contributed to low observed rates of pre-TRT testosterone deficiency and post-TRT testosterone monitoring. We are also unable to verify whether serum testosterone measurements were obtained as recommended in the morning, when levels are most predictable [3]. Finally, due to data limitations, we cannot comment on symptoms, other patient factors or provider factors driving these TRT practices. The strength of our study is comprehensive laboratory, clinical and medication data from a large and geographically diverse cohort reflecting routine care of HIV-infected men in the USA.

In conclusion, HIV-infected men initiate TRT at high rates, potentially without baseline testosterone deficiency or recommended posttreatment monitoring. Overuse of TRT can increase the risks of erythrocytosis, metastatic prostate cancer, reduced sperm production and infertility [3]. Further, TRT has been associated with myocardial infarction in those with preexisting cardiovascular disease [9], which may be conferred by HIV infection itself [20,21]. TRT data capture and reporting should be prioritized in HIV research agendas, and subsequent studies will evaluate outcomes and causes of TRT in HIV-infected men.

\section{Acknowledgements}

R.B. and A.M. developed the study concept. R.B. prepared the initial manuscript draft. C.A. performed the data analysis, and C.A. and A.M. contributed to manuscript preparation. All authors reviewed and edited the manuscript.

This work was supported by the Creative and Novel Ideas in HIV Research (CNIHR) Award from the U.S. National Institutes of Health (NIH) Office of AIDS Research and the NIH-funded Centers for AIDS Research [grant number 60032569]; the National Institute of Allergy and Infectious Diseases at the NIH [grant numbers R24 AI067039, P30 AI027757 and P30 AI50410]; and the National Center for Advancing Translational Sciences at the NIH [grant number KL2 TR000421].

These findings are presented on behalf of the Centers for AIDS Research Network of Integrated Clinical Systems (CNICS). We thank all of the CNICS investigators, data management teams and patients who contributed to this project.

\section{References}

1. Handelsman DJ. Global trends in testosterone prescribing, 2000-2011: expanding the spectrum of prescription drug misuse. Med J Aust. 2013; 199:548-551. [PubMed: 24138381]

2. Baillargeon J, Urban RJ, Ottenbacher KJ, Pierson KS, Goodwin JS. Trends in androgen prescribing in the United States, 2001 to 2011. JAMA Intern Med. 2013; 173:1465-1466. [PubMed: 23939517]

3. Bhasin S, Cunningham GR, Hayes FJ, Matsumoto AM, Snyder PJ, Swerdloff RS, et al. Testosterone therapy in men with androgen deficiency syndromes: an Endocrine Society clinical practice guideline. J Clin Endocrinol Metab. 2010; 95:2536-2559. [PubMed: 20525905]

4. Katz A, Katz A, Burchill C. Androgen therapy: testing before prescribing and monitoring during therapy. Can Fam Physician. 2007; 53:1936-1942. [PubMed: 18000271]

5. Layton JB, Li D, Meier CR, Sharpless J, Sturmer T, Jick SS, et al. Testosterone lab testing and initiation in the United Kingdom and the United States, 2000-2011. J Clin Endocrinol Metab. 2014; 99:835-842. [PubMed: 24423353]

6. Wolfe SM. Increased heart attacks in men using testosterone: the UK importantly lags far behind the US in prescribing testosterone. BMJ. 2014; 348:g1789. [PubMed: 24578515] 
7. Xu L, Freeman G, Cowling BJ, Schooling CM. Testosterone therapy and cardiovascular events among men: a systematic review and meta-analysis of placebo-controlled randomized trials. BMC Med. 2013; 11:108. [PubMed: 23597181]

8. Basaria S, Coviello AD, Travison TG, Storer TW, Farwell WR, Jette AM, et al. Adverse events associated with testosterone administration. N Engl J Med. 2010; 363:109-122. [PubMed: 20592293]

9. Finkle WD, Greenland S, Ridgeway GK, Adams JL, Frasco MA, Cook MB, et al. Increased risk of nonfatal myocardial infarction following testosterone therapy prescription in men. PLoS One. 2014; 9:e85805. [PubMed: 24489673]

10. Vigen R, O'Donnell CI, Baron AE, Grunwald GK, Maddox TM, Bradley SM, et al. Association of testosterone therapy with mortality, myocardial infarction, and stroke in men with low testosterone levels. JAMA. 2013; 310:1829-1836. [PubMed: 24193080]

11. Glueck CJ, Wang P. Testosterone therapy, thrombosis, thrombophilia, cardiovascular events. Metabolism. 2014; 63:989-994. [PubMed: 24930993]

12. Crum NF, Furtek KJ, Olson PE, Amling CL, Wallace MR. A review of hypogonadism and erectile dysfunction among HIV-infected men during the pre and post-HAART eras: diagnosis, pathogenesis, and management. AIDS Patient Care STDS. 2005; 19:655-671. [PubMed: 16232050]

13. Wunder DM, Bersinger NA, Fux CA, Mueller NJ, Hirschel B, Cavassini M, et al. Hypogonadism in HIV-1-infected men is common and does not resolve during antiretroviral therapy. Antivir Ther. 2007; 12:261-265. [PubMed: 17503668]

14. Ashby J, Goldmeier D, Sadeghi-Nejad H. Hypogonadism in human immunodeficiency viruspositive men. Korean J Urol. 2014; 55:9-16. [PubMed: 24466391]

15. Purcell DW, Wolitski RJ, Hoff CC, Parsons JT, Woods WJ, Halkitis PN. Predictors of the use of viagra, testosterone, and antidepressants among HIV-seropositive gay and bisexual men. AIDS. 2005; 19(Suppl 1):S57-S66. [PubMed: 15838195]

16. Kitahata MM, Rodriguez B, Haubrich R, Boswell S, Mathews WC, Lederman MM, et al. Cohort profile: the Centers for AIDS Research Network of Integrated Clinical Systems. Int J Epidemiol. 2008; 37:948-955. [PubMed: 18263650]

17. Grinspoon S. Androgen deficiency and HIV infection. Clin Infect Dis. 2005; 41:1804-1805. [PubMed: 16288407]

18. Freitas, P.; Lau, E.; Matos, MJ.; Serrão, R.; Xerinda, S.; Sarmento, A.; Carvalho, D. Endo 2013. San Francisco, CA: 2013 Jun 15-18. Prevalence of biochemical hypogonadism in HIV-1-infected patients on antiretroviral therapy [Abstract].

19. Monroe AK, Dobs AS, Palella FJ, Kingsley LA, Witt MD, Brown TT. Morning free and total testosterone in HIV-infected men: implications for the assessment of hypogonadism. AIDS Res Ther. 2014; 11:6. [PubMed: 24450960]

20. Freiberg MS, Chang CC, Kuller LH, Skanderson M, Lowy E, Kraemer KL, et al. HIV infection and the risk of acute myocardial infarction. JAMA Intern Med. 2013; 173:614-622. [PubMed: 23459863]

21. Silverberg MJ, Leyden WA, Xu L, Horberg MA, Chao CR, Towner WJ, et al. Immunodeficiency and risk of myocardial infarction among HIV-positive individuals with access to care. J Acquir Immune Defic Syndr. 2014; 65:160-166. [PubMed: 24442222] 
Table 1

Testosterone replacement therapy initiation rates and rate ratios of HIV-infected men in Centers for AIDS Research Network of Integrated Clinical Systems stratified by characteristics at cohort entry.

\begin{tabular}{|c|c|c|c|c|c|c|c|c|}
\hline & $N$ & TRT events & Person-years (py) & Rate (per 1000 py) & IRR & $95 \% \mathrm{CI}$ & $\mathrm{HR}^{a}$ & $95 \% \mathrm{CI}$ \\
\hline Overall & 14454 & 1482 & 75173 & 19.7 & - & $18.7-20.7$ & - & - \\
\hline \multicolumn{9}{|l|}{ Age (years) } \\
\hline$\leq 34$ & 4795 & 323 & 25231 & 12.8 & 1.0 & - & 1.0 & - \\
\hline $35-50$ & 8042 & 959 & 42865 & 22.4 & 1.75 & $1.54-1.98$ & 1.58 & $1.37-1.83$ \\
\hline$>50$ & 1617 & 200 & 7077 & 28.3 & 2.21 & $1.85-2.63$ & 1.82 & $1.48-2.24$ \\
\hline \multicolumn{9}{|l|}{ Race } \\
\hline Nonwhite & 7196 & 508 & 37063 & 13.7 & 1.0 & - & 1.0 & - \\
\hline White & 7258 & 974 & 38110 & 25.6 & 1.86 & $1.68-2.07$ & 1.72 & $1.51-1.96$ \\
\hline \multicolumn{9}{|l|}{ HIV risk factor } \\
\hline Non-MSM & 4535 & 391 & 24439 & 16.0 & 1.0 & - & 1.0 & - \\
\hline MSM & 9919 & 1091 & 50734 & 21.5 & 1.34 & $1.20-1.51$ & 1.12 & $0.97-1.29$ \\
\hline \multicolumn{9}{|l|}{ AIDS wasting } \\
\hline No & 13940 & 1371 & 72390 & 18.9 & 1.0 & - & 1.0 & - \\
\hline Yes & 514 & 111 & 2784 & 39.9 & 2.11 & $1.74-2.55$ & 2.07 & $1.64-2.60$ \\
\hline \multicolumn{9}{|l|}{ Hepatitis B } \\
\hline No & 13361 & 1354 & 68930 & 19.6 & 1.0 & - & 1.0 & - \\
\hline Yes & 1093 & 128 & 6244 & 20.5 & 1.04 & $0.87-1.25$ & 1.10 & $0.92-1.37$ \\
\hline \multicolumn{9}{|l|}{ Hepatitis C } \\
\hline No & 10983 & 1099 & 55508 & 19.8 & 1.0 & - & 1.0 & - \\
\hline Yes & 3471 & 383 & 19666 & 19.5 & 0.98 & $0.88-1.10$ & 1.2 & $1.04-1.38$ \\
\hline \multicolumn{9}{|l|}{ ART type } \\
\hline None & 4335 & 370 & 24097 & 15.4 & 1.0 & - & 1.0 & - \\
\hline Non-PI-based & 4819 & 397 & 22559 & 17.6 & 1.15 & $1.00-1.32$ & 1.02 & $0.86-1.21$ \\
\hline PI-based & 5300 & 715 & 28517 & 25.1 & 1.63 & $1.44-1.85$ & 1.44 & $1.23-1.68$ \\
\hline \multicolumn{9}{|c|}{ Nadir CD4 ${ }^{+}$cell count (cells/ $\left.\mu \mathrm{l}\right)$} \\
\hline 2500 & 2464 & 212 & 12221 & 17.4 & 1.0 & - & 1.0 & - \\
\hline $350-499$ & 2515 & 221 & 12965 & 17.1 & 0.98 & $0.82-1.18$ & 1.02 & $0.83-1.26$ \\
\hline $201-349$ & 3434 & 334 & 18156 & 18.4 & 1.06 & $0.89-1.26$ & 1.10 & $0.90-1.34$ \\
\hline $\mathcal{2} 00$ & 6041 & 715 & 31831 & 22.5 & 1.29 & $1.11-1.51$ & 1.23 & $1.02-1.49$ \\
\hline \multicolumn{9}{|l|}{ HIV RNA (copies/ml) } \\
\hline$\$ 500$ & 1983 & 195 & 8858 & 22.0 & 1.0 & - & 1.0 & - \\
\hline$>500$ & 12471 & 1287 & 66316 & 19.4 & 0.88 & $0.76-1.02$ & 1.03 & $0.86-1.23$ \\
\hline \multicolumn{9}{|l|}{ BMI $\left(\mathrm{kg} / \mathrm{m}^{2}\right)$} \\
\hline 230.0 & 1329 & 139 & 6329 & 22.0 & 1.0 & - & 1.0 & - \\
\hline $25.0-29.9$ & 3486 & 371 & 17799 & 20.8 & 0.95 & $0.78-1.15$ & 0.87 & $0.72-1.06$ \\
\hline $18.5-24.9$ & 5891 & 630 & 29636 & 21.3 & 0.97 & $0.81-1.16$ & 0.90 & $0.74-1.08$ \\
\hline$<18.5$ (underweight) & 416 & 51 & 1948 & 26.2 & 1.19 & $0.87-1.64$ & 1.14 & $0.82-1.58$ \\
\hline Unknown & 3332 & 291 & 19461 & 15.0 & 0.68 & $0.56-0.83$ & - & - \\
\hline
\end{tabular}




\begin{tabular}{|c|c|c|c|c|c|c|c|c|}
\hline & $N$ & TRT events & Person-years (py) & Rate (per 1000 py) & IRR & $95 \% \mathrm{CI}$ & $\mathrm{HR}^{a}$ & $95 \%$ CI \\
\hline \multicolumn{9}{|l|}{ Smoking ever } \\
\hline Yes & 5566 & 483 & 32422 & 14.9 & 1.0 & - & 1.0 & - \\
\hline Never or unknown & 8888 & 999 & 42752 & 23.4 & 1.57 & $1.41-1.75$ & 1.13 & $0.98-1.31$ \\
\hline \multicolumn{9}{|l|}{ Alcohol abuse ever } \\
\hline Yes & 2867 & 265 & 17097 & 15.5 & 1.0 & - & 1.0 & - \\
\hline Never or unknown & 11587 & 1217 & 58076 & 21.0 & 1.35 & $1.19-1.54$ & 0.90 & $0.76-1.06$ \\
\hline
\end{tabular}

ART, antiretroviral therapy; $\mathrm{CD}^{+}, \mathrm{CD} 4^{+} \mathrm{T}$-lymphocyte cell count; PI, protease inhibitor.

${ }^{a}$ Multivariable Cox regression modelling using all variables listed in the table and CNICS site. 